Jurnal Ilmu Budaya, Vol. 17, No. 2 Februari Tahun 2021

\title{
REPRESENTASI, RELASI, DAN IDENTITAS UNDANG-UNDANG LAUT: KAJIAN EKOLINGUISTIK KRITIS
}

\author{
Mohd. Fauzi ${ }^{1}$, Hermansyah ${ }^{2}$ \\ 12Universitas Lancang Kuning \\ Email:fauzi@unilak.ac.id
}

\begin{abstract}
This study aims to reveal the representation, relations and identity of the Maritime Laws using a critical ecolinguistic approach. This linguistic phenomenon is a treasure trove of Malay intellectual property in the past. This type of research is literature research with a qualitative descriptive method. The data was collected by using the method of observing free and speaking with observation and note taking techniques. The data analysis used the mix and match methods, especially referential equivalents, translational equivalents and pragmatic equivalents. The results of data analysis were explained using informal methods. The data used is written data from the Malay Maritime Laws. The results shown that the contents of the text of the Malay Maritime Laws are related to the duties and obligations of seafarers who sail. Ecolexicons, phrases and sentences related to marine and shipping existed at that time. This fact occurs because the sea has been the lifeblood of the Malay people for centuries and will continue to be passed on to future generations.
\end{abstract}

Keywords: Maritime Laws, Ecolinguistics, Representation, Relation and Identity

\section{Pendahuluan}

Undang-Undang Laut (UUL) yang berasal dari zaman Melaka adalah salah satu undang-undang yang sangat penting di Nusantara. Undangundang ini berisi tugas dan kewajiban para pelaut yang melakukan pelayaran. Para pemimpin Melayu dahulu (pemroduksi teks) sangat menyadari bahwa laut menjadi urat nadi yang sangat penting bagi bangsa Melayu. Berbagai aktifitas dilakukan di atas laut misalnya sebagai media transportasi, bisnis, urusan kenegaraan dan laut sangat kaya dengan sumber daya alam. Laut juga merupakan zona kedaulatan yang harus dijaga, karena jika laut jatuh ke tangan musuh, maka kedaulatan Melayu akan lumpuh. 
Jurnal Ilmu Budaya, Vol. 17, No. 2 Februari Tahun 2021

Masyarakat Melayu sendiri sangat menggantungkan hidupnya dengan hasil-hasil laut. Terbukti, selama berabad-abad, negeri-negeri Melayu makmur dari hasil lautnya.

UUL berisi ekoleksikon, frasa maupun kalimat berupa perkaraperkara yang mesti dilakukan oleh pelayar dan denda-denda maupun hukuman bagi yang melanggar. Undang-undang ini juga memuat istilah-istilah khusus pelayaran dan kelautan yang tidak mudah dipahami oleh orang-orang yang bukan pelaut ataupaun orang yang terbiasa melaut. Khazanah kebahasaan ini lama kelamaan akan dilupakan orang dan bisa jadi hilang ditelan zaman. Menariknya, teks yang terdapat dalam UUL laut tersebut berkaitan dengan bahasa lingkungan pada ranah kelautan. Fenomena kebahasaan ini tentulah sangat penting untuk dikaji agar khazanah kearifan lokal Melayu ini dapat diungkap dan dapat diwariskan kepada generasi mendatang. Hal ini senada dengan pendapat Sinar (2010:70) "banyak bahasa daerah di belahan dunia ini termasuk Indonesia berada di ambang kritis, semakin sulit untuk bertahan hidup, berfungsi, dan terwariskan secara utuh. Banyak nilai kearifan dan pengetahuan asli lokal yang tergusur dan punah. Belum lagi, dengan ancaman hegemoni dan dominasi beberapa bahasa internasional, regional dan nasional, semakin mendesak bahasa-bahasa minoritas".

Sebenarnya sudah banyak penelitian tentang bahasa Melayu berupa penelitian lapangan maupun penelitian kepustakaan yang bersumber dari cerita rakyat, syair, gurindam, tunjuk ajar Melayu dan lain sebagainya, namun penelitian yang fokus kajiannya bahasa dan lingkungan keairan belum banyak dilakukan. Kondisi ini tentu sangat disayangkan karena di Riau banyak teks berbasis lingkungan, dan masyarakat Riau yang tinggal berdampingan dengan wilayah perairan banyak menghasilkan teksteks yang berkaitan keairan. 
Jurnal Ilmu Budaya, Vol. 17, No. 2 Februari Tahun 2021

\begin{tabular}{lll}
\hline \multicolumn{2}{c}{ Penelitian terdahulu yang } & UUL. Kajian ini tentulan menjadi \\
mengungkap bahasa dan lingkungan & suatu keharusan untuk dilakukan \\
keairan antara lain; Mahardhika \& & karena teks dalam UUL adalah teks \\
Kramadibrata (2020) "Sanksi Pidana & lama yang sarat dengan kearifan lokal \\
dalam Teks Naskah Undang-Undang & masyarakat Melayu yang terkait \\
Hukum Laut”; Jismulatif dan & dengan pelestarian kelautan. Jika \\
Dahnilsyah (2019) "Language and & kajian ini tidak dilakukan maka \\
ecology in Ecolinguistics Perspective: & fenomena bahasa ini tidak terungkap \\
A Case Study on Tunjuk Ajar Melayu & dan informasi-informasi penting di \\
in Riau, Indonesia"; Junaidi (2019) & dalamnya tidak dapat dinikmati oleh \\
"Spirit of Maritime in Rida K Liamsi's & generasi berikutnya.
\end{tabular}

Poems"; Edorita (2018) "Implementasi

Nilai-nilai Adat dan Kearifan Lokal

dalam Melestarikan Hutan, Sungai dan

\section{Konsep}

Penelitian ini menggunakan teori

Danau Desa Buluh Cina Kecamatan

Siak Hulu, Kabupaten Kampar";

Samin (2018) "Lancang Kuning dan

kearifan lokal masyarakat Melayu

Bintan Kepulauan Riau"; Hijiriah (2017) "Kearifan Lokal Cerita Rakyat Masyarakat Kabupaten Karimun

Kepulauan Riau"; dan Suwardi (2016)

"Undang-Undang Laut Dalam Sejarah

Kesusastraan Melayu Klasik”.

Dari penelusuran literatur, kajian-kajian relevan sebelumnya belum ada yang membahas analisis wacana kritis Fairclough (1995) dan ekolinguistik kritis Stibbe (2015). Teori Critical Discourse Analysis Fairclough dengan menitik beratkan pada tiga level. Pertama, setiap teks memiliki fungsi, yaitu representasi, relasi, dan identitas. Kedua, praktik wacana yang meliputi cara-cara teks di produksi. Ketiga, praktik sosiokultural yang berkaitan dengan tingkat situasional, berkaitan dengan produksi dan konteks situasinya.

representasi, relasi dan identitas dalam 
Jurnal Ilmu Budaya, Vol. 17, No. 2 Februari Tahun 2021

Pada tataran representasi,

lingkungan. Fill

$(1993: 126)$

persoalan yang ingin diungkap adalah

mendefinisikan "Ecolinguistics is an bagaimana seseorang, kelompok, umbrella term for '[...] all approaches tindakan, kegiatan ditampilkan dalam teks. Tindakan representasi menjadi perwujudan hubungan-hubungan kekuasaan dalam masyarakat (Eriyanto, 2009: 290). Pada tataran relasi, diungkap keterkaitan antar partisipan yang terlibat ditampilkan dalam teks. Partisipan yang dimaksud antara lain wartawan, redaktur, khalayak pembaca, dan tokoh masyarakat (Eriyanto, 2009: 300).

Selanjutnya pada tataran identitas, Eriyanto (2009:303) menyebutkan bahwa bagaimana identitas wartawan, khalayak, dan partisipan berita ditampilkan dan digambarkan dalam teks.

Untuk mengungkap representasi, relasi dan identitas dalam UUL digunakan konsep ekolinguistik kritis. Dipilihnya konsep eklinguistik kritis karena pada dasarnya ekolinguistik bisa digunakan pada semua bidang ilmu bahasa yang mengkombinasikan bahasa dan in which the study of language (and languages) is in any way combined with ecology'. 'Ekolinguistik merupakan payung penelitian bahasabahasa yang dikombinasikan dengan ekologi'.

Ekolinguistik adalah gabungan dua kata yaitu ekologi dan linguistik, yang artinya bahasa-bahasa lingkungan. Perubahan bahasa, terutama pada tataran leksikon, tidak dapat dipisahkan dari perubahan lingkungan alam karena bahasa dan lingkungannya merupakan dua hal yang saling memengaruhi. Fenomena ini merupakan bidang kajian ekolinguistik, yaitu suatu disiplin ilmu yang mengkaji bahasa dan lingkungannya dan menyandingkan ekologi dengan linguistik (Mbete, 2009:1).

Stibbe

(2015:183-184)

menyatakan bahwa "Ekolinguistik menganalisis bahasa yang mengungkap kisah-kisah hidup 
Jurnal Ilmu Budaya, Vol. 17, No. 2 Februari Tahun 2021

manusia, kisah-kisah tersebut dinilai

dengan konsep filsafat. Kisah-kisah

yang bersifat konstruktif terhadap

filsafat penyelamatan lingkungan patut

didukung dan kisah-kisah yang

bersifat destruktif terhadap filsafat

pelestarian alam patut di tentang, dan mencari kisah-kisah baru... ".

\section{Metodologi Penelitian}

Jenis penelitian ini adalah deskriptif kualitatif. Penelitian deskriptif kualitatif merupakan penelitian yang bertujuan membuat deskripsi, membuat gambaran, lukisan secara sistematis, faktual dan akurat mengenai data, sifat-sifat serta hubungan fenomena-fenomena yang diteliti. Pemilihan jenis penelitian deskriptif di dalam penelitian bahasa, cenderung digunakan terutama dalam mengumpulkan data serta menggambarkan data secara ilmiah (Djajasudarma, 2006:9). Sumber data penelitian ini adalah teks UUL, sedangkan datanya adalah ekoleksikon, frasa dan kalimat-kalimat yang berkaitan dengan lingkungan (ekolinguistik) dalam UUL yang terdapat dalam buku Sejarah Kesusasteraan Klasik yang dihimpun oleh Liaw Yock Fang dan diterbitkan oleh Yayasan Pustaka Obor Indonesia tahun 2016. Pengumpulan data menggunakan teknik catat (Sudaryanto, 2016).

Penyajian hasil analisis data dalam penelitian ini dilakukan dengan menggunakan metode informal dan formal. Penyajian informal yaitu berupa rumusan dengan menggunakan kata-kata biasa, sedangkan penyajian formal adalah perumusan dengan tanda dan lambang-lambang (Sudaryanto, 2016). Demikian juga menurut Mahsun (2005:123) bahwa metode informal merupakan perumusan dengan menggunakan terminologi yang bersifat teknis, dan metode formal merupakan perumusan dengan menggunakan tanda-tanda atau lambang-lambang.

Alasan digunakannya metode informal dan formal dalam penyajian hasil analisis karena penelitian ini bersifat deskriptif. Maksudnya 
Jurnal Ilmu Budaya, Vol. 17, No. 2 Februari Tahun 2021

pendeskripsian dari gejala atau

keadaan yang terjadi pada data penelitian. Penggunaan kedua metode tersebut karena selain penyajian dilakukan dengan menggunakan katakata biasa juga dengan menggunakan tanda dan lambang-lambang.

\section{Hasil dan Pembahasan}

Pada unsur representasi, yang dibahas adalah peristiwa-peristiwa yang terjadi di dalam teks UUL yang meliputi lingkungan pelayaran, keterlibatan kelompok maupun perorangan, situasi dan pertistiwaperistiwa dalam teks, dan fenomena sosial yang muncul dalam teks tersebut. Pada tataran relasi, dijelaskan bagaimana hubungan antara pemroduksi teks, pihak-pihak yang terlibat dalam teks-teks, serta khalayak atau penerima (konsumen) teks. Pada bagian identitas, dijelaskan bagaimana identitas pemroduksi teks (produsen) tampak dan tergambar dalam teks. Dalam pembahasannya juga disertai analisis produksi teks, penyebaran teks dan konsumsi teks (meso-struktural).
Pembahasan ini menjelaskan tiga unsur penting terkait representasi, relasi dan identitas teks-teks keairan Melayu Riau terhadap (1) lingkungan kelautan, (2) lingkungan sosial dan budaya Melayu dan (3) Nilai-nilai Keislaman yang terungkap dalam teks. Representasi, relasi dan identitas teks UUL dapat dicermati pada data berikut.

Data (1)

Tugas segala nakhoda dan awak perahu, misalnya tukang agung, tukang tengah, tukang kanan, tukang kiri, juru mudi, juru batu, gantung dan senawi (UUL: Butir 1.1.)

Awak perahu yang melawan nakhoda dan tukang akan dipalu (UUL: Butir 1.2.)

Orang yang berzina dengan istri orang di dalam jung akan dibunuh; kalau perempuan itu merdeka lagi bujang, dipalu dan kemudian dinikahkan. Tetapi orang yang berzina dengan abdi hanya akan didenda. Kalau abdi itu sudah lama dipakai tuannya, didenda boleh, dibunuh pun boleh. Abdi yang berzina dengan abdi akan dipalu ramairamai.(UUL: Butir 2.)

Pada bagian pendahuluan UUL ditampilkan job description (deskripsi 
Jurnal Ilmu Budaya, Vol. 17, No. 2 Februari Tahun 2021

tugas) masing-masing petugas mulai dari Nakhoda sampai Senawi. Meskipun tugas-tugas tersebut tidak disebutkan secara rinci tetapi sepertinya pembuat UUL ini memandang sangat penting sehingga diletakkan pada bagian awal.

1. Nakhoda adalah kapten kapal yang menjadi pemimpin tertinggi dalam sebuah kapal. Tugasnya adalah memimpin dan mengurus kapal administrasi kapal. Untuk menjadi seorang nakhoda tidaklah gampang, dia mestilah memahami seluk beluk pelayaran, manajemen kapal, membaca arah angin dan perkara penting lainnya. Jika seorang nakhoda tidak paham dengan situasi kapal, pelayaran dan kelautan maka sebagaimana dinukilkan dalam lagu Lancang Kuning "Bila nakhoda kuranglah paham, maka kapal akan tenggelam". Seorang nakhoda juga berhak mengizinkan atau menolak penumpang yang ingin turut serta berlayar atas pertimbangan keselamatan dan kelancaran pelayaran.

2. Awak perahu, orang yang bekerja di kapal yang bekerja atas keinginan sendiri atau karena hamba sahaya atau karena memiliki hutang kepada tuannya.

3. Tukang Agung (kepala tukang), bertugas membantu mualim mengurus layar besar.

4. Tukang Tengah, bertugas mengurus bagian tengah kapal.

5. Tukang Kiri, bertugas pada bagian kiri kapal.

6. Juru mudi, bertugas mengemudikan kapal, dan bertanggungjawab untuk mengawasi serta mengatur semua senjata-senjata yang ada di dalam kapal. Apabila terjadi serangan, misalnya oleh bajak laut, seorang juru mudi harus berperan sebagai orang yang paling depan dalam menangkal serangan-serangan tersebut (Swantoro, 2015).

7. Juru Batu, adalah awak perahu yang kerjanya menduga laut 
Jurnal Ilmu Budaya, Vol. 17, No. 2 Februari Tahun 2021

(KBBI, 2005: 482) atau ditampilkan peran dan tugas masingmengatur jangkar dan masing pelayar. Semua itu harus bertanggungjawab di kapal bagian depan (Swantoro, 2015).

8. Tukang gantung, bertugas menggantung layar.

9. Senawi, adalah penumpang perahu yang yang membayar biaya dengan tenaga (menolong, mengayuh, dsb).

10. Jong atau balok adalah perahu atau kapal.

Dilihat dari aspek ekolinguistik kritis, aspek kebahasaan pada data (1) di atas menampilkan Nakhoda, Tukang Agung, Tukang Tengah, Tukang Kanan, Tukang Kiri, Juru Mudi, Juru Batu, Gantung dan Senawi yang merupakan hiponim dari job description (deskripsi tugas) dalam kapal. Leksikon jong atau balok juga merupakan istilah yang biasa dipakai masyarakat Melayu. Istilah-istilah ini hanya ada di lingkungan pelayaran pada masa lampau. Data (1) ini merepresentasikan loyalitas bawahan kepada atasan, antara nakhoda dan anak buah kapal. Pada teks ini

Data (2)

Segala orang muda-muda mesti hati-hati mengerjakan pekerjaannya dan menemani nakhoda kemana-mana apabila sampai ke bandar orang/mesti berperang dengan sungguhsungguh apabila bertemu dengan musuh. (UUL: Butir 12.2.) 
Jurnal Ilmu Budaya, Vol. 17, No. 2 Februari Tahun 2021

Data (2) di atas Adat yang taat beragama, sehingga merepresentasikan betapa besar nilai-nilai di dalam Undang-Undang perhatian orang terhadap nakhoda. Hal Laut ini tidak terlepas dari nilai-nilai ini menunjukkan bahwa seorang keislaman. Melalui teks pada data (1) pemimpin sangat dihargai dan dimuliakan karena pemimpin menjadi panutan. Jika sesuatu yang buruk menimpa nakhoda maka misi pelayaran terganggu dan bisa jadi pelayaran mereka gagal. Disamping itu juga, menyeberangi laut bukanlah persoalan sepele tetapi mesti diperhitungkan segala sesuatunya. Representasi selanjutnya adalah ketaatan orang Melayu terhadap nilainilai keislaman. Hal ini dapat dilihat pada butir (2) Berzina di dalam kapal merupakan pekerjaan yang sangat terlarang, hukumannya pun sangat berat. Hukuman yang sangat berat adalah jika berzina dengan istri orang yakni dihukum bunuh. Berzina dengan abdi hukumannya didenda, tetapi boleh juga dibunuh. Jika yang berzina adalah abdi dengan abdi, maka hukumannya dipalu ramai-ramai.

Teks UUL dibuat oleh para Sultan, Pemuka Agama, dan Pemuka 
Jurnal Ilmu Budaya, Vol. 17, No. 2 Februari Tahun 2021

ditaati. Bagi bangsa Melayu, laut menjadi sarana sangat penting bagi kerajaan dan rakyat keseluruhan. Nakhoda dan Awak Kapal menjadi pekerjaan yang populer, memerlukan keahlian dan pedoman yang diatur oleh kerajaan.

Yang membuat Undang-Undang Laut ini adalah para pemimpin Melayu, sehingga legalitasnya sangat jelas. Undang-Undang ini diakui di seluruh negeri Melayu di Nusantara, sehingga orang luar pun segan dan mentaati aturan ini jika melalui perairan Melayu. Kerajaan-kerajaan di Riau yang pada waktu itu tidak mengenal dan belum ada batas teritorial negara kesatuan Republik Indonesia menggunakan UndangUndang ini.

Lahirnya Undang-Undang (Analisis Praktik Sosial Budaya) yang dibuat oleh para pemimpin Melayu karena nilai dan manfaatnya yang sangat penting bagi kerajaan dan masyarakat. Di dalam dunia Melayu, segala sesuatu dibuat UndangUndangnya agar setiap orang memiliki batu pijakan yang jelas dalam bertindak. Yang lebih penting lagi, laut merupakan dunianya orang Melayu sebagai tempat mencari makan, dan jalan menuju ke berbagai negeri.

Dari fakta ini dapat diketahui bahwa masyarakat Melayu pada waktu itu sudah sangat memahami persoalan aktivitas di atas laut yang harus diatur. Aturan ini diperlukan agar Nakhoda dan awak kapal tidak sesuka hati bertindak kepada anak buah kapal atau kepada para penumpangnya. Demikian juga dengan awak kapal, tidak boleh lalai dengan tugasnya.

Frasa akan dipalu, akan dibunuh dan akan dipalu ramai-ramai pada data (1) butir (1.1) merupakan satuan lingual yang bermakna negatif tetapi berimplikasi positif karena hukuman berat bagi orang-orang yang melanggar hukum akan membuat pelakunya jera dan menjadi pelajaran bagi orang lain untuk tidak melakukan kejahatan yang sama. Jika orang-orang tidak loyal dan disiplin dengan aturan maka tujuan pelayaran tidak tercapai. Data (1) secara implisit menekankan 
Jurnal Ilmu Budaya, Vol. 17, No. 2 Februari Tahun 2021

pada aturan-aturan yang berlaku dalam

dunia Melayu yang ada kaitannya antara kehidupan sosial dan Islam. Aturan ini menjelaskan hukuman bagi orang-orang yang melakukan zina di dalam kapal. Berzina dengan istri orang maka hukumannya adalah dibunuh. Jika berzina dengan perempuan yang belum menikah hukumannya sedikit lebih ringan yakni dipukuli dan selanjutnya dinikahkan. Jika berzina dengan budaknya hukumannya adalah didenda. Jika berzina dengan budak yang sudah dipakai tuannya, boleh bayar denda dan boleh juga di bunuh, namun jika yang berzina itu budak dengan budak maka hukumannya adalah dipukuli ramai-ramai. Aturan yang dibuat ini sangat selaras dengan hukum-hukum Islam, sehingga masyarakat Melayu memahami aturan-aturan ini, karena mereka menyadari bahwa aturanaturan ini dibuat untuk kebaikan bersama untuk generasi saat ini dan juga diwariskan pada generasi berikutnya.
Disamping mengikuti aturan Islam, dapat dipahami bahwa pekerjaan berlayar adalah pekerjaan berat dan beresiko, sehingga pekerjaan dosa seperti zina dapat merusak nilai suci misi pelayaran. Perbuatan dosa semisal zina dapat mendatangkan sial atau petaka dalam usaha mereka menyeberangi lautan.

Perkara selanjutnya yang diatur dalam UUL adalah peran mualim, seperti pada data berikut.

Data (3)

Mualim tidak boleh meninggalkan jung sebelum habis perjanjian. (UUL: Butir 8.3.)

Mualim adalah orang yang mengatur jalannya kapal. Mualim ibarat hakim di lautan karena bertanggungjawab dalam mengatur arah kapal agar sesuai dengan tujuan. Pada umumnya, terdapat dua orang mualim dalam satu kapal, yakni mualim besar dan mualim kecil. Mualim kecil bertugas mengurusi layar-layar kapal sesuai dengan arah angin. Mualim besar bertugas 
Jurnal Ilmu Budaya, Vol. 17, No. 2 Februari Tahun 2021

mengatur arah tujuan kapal dan wajib mengingat arah tujuan kapal yang benar. Seorang mualim juga harus mengetahui seluk-beluk kondisi lautan, letak pulau-pulau, arah angin, gelombang, arus, kedalaman lautan, posisi bulan dan bintang-bintang, tahun-tahun, musim-musim, telukteluk, tanjung, pantai-pantai, batu-batu karang, dan hal-hal teknis lainnya. Mualim memperoleh upah dari nakhoda, yakni sebagian dari muatan kapal sampai dengan harga satu setengah tail (Swantoro, 2015).

Pihak lain yang disebut dalam UUL adalah keberadaan kiwi, seperti dapat dilihat pada data berikut.

Data (4)

Kiwi yang sudah memberi cukai tidak kena cukai negeri. Mulkiwi adalah penghulu segala kiwi, tetapi dalam semua hal, ia mesti musyawarat dengan semua kiwi. (UUL: Butir 9.2.)

\begin{tabular}{lcr}
\multicolumn{1}{c}{ Satuan } & lingual & yang \\
direpresentasikan & dalam data & $(4)$ \\
merupakan & wacana & yang \\
mengambarkan & peran kiwi maupun \\
mulkiwi dalam sebuah pelayaran. Kiwi \\
(mala kiwi atau saudagar), adalah
\end{tabular}

orang yang hendak menumpang kapal dengan tujuan untuk berdagang ke pelabuhan-pelabuhan tertentu. Seorang kiwi biasanya akan menitipkan barang muatannya ke dalam kapal. Menurut aturan, kiwi harus membayar sebesar tonnase yang mereka punyai kecuali jika mereka membantu nakhoda dalam urusan perniagaan, sebanyak 3 atau 4 tail (24 atau 30 dollar). Nakhoda pun akan memberi upah kepada kiwi yang membantunya, misalnya diberi sebagian dari isi kapal atau sesuai kesepakatan sebelumnya. Selain itu, para kiwi juga bisa berperan sebagai penasehat nakhoda jika sewaktu-waktu terjadi masalah di atas kapal (Swantoro, 2015)

Kalimat yang digunakan pada data (4) adalah kalimat pernyataan, dan dalam mewacanakan pasal ini, cenderung menunjukkan peran kiwi dalam pelayaran. Selanjutnya dari segi relasi, wacana pada data (3) menunjukkan peran penting kiwi terhadap kerajaan yang membayar cukai dan mempunyai hak untuk dilindungi. Para Sultan dan pemimpin 
Jurnal Ilmu Budaya, Vol. 17, No. 2 Februari Tahun 2021

Melayu (identitas pemroduksi teks

UUL) mengatur sedemikian rupa setiap pihak yang terlibat dalam pelayaran termasuk kiwi. Demikian juga dalam persoalan penyelamatan orang yang terdampar maupun memerlukan pertolongan yang ditemukan dalam pelayaran seperti dapat dicermati pada data berikut.

Data (5)

Orang yang diselamatkan dari pulau atau laut mesti membayar gantung layar (ganjaran) setengah tahil emas; kalau ada hartanya yang lepas sepaha (1/4 tahil). (UUL: Butir 4.1.)

Data (5) mengungkap persoalan orang yang diselamatkan dari pulau atau laut karena terdampar atau karena kapal pecah terhempas badai atau juga karena dirampok oleh para lanun. Orang yang diselamatkan tersebut mestilah membayar denda sebanyak 1 tahil = 16 mas (64 kupang) atau 1 paha $=1 / 4$ tahil (4 mas). Denda ini diberlakukan sebagai bentuk tanggungjawab moralnya kepada orang yang telah menyelamatkan dirinya (representasi). Ditinjau dari relasinya, wacana dalam teks data (5) menggambarkan tanggung jawab kemanusiaan untuk menolong siapa saja yang membutuhkan pertolongan dalam pelayaran tetapi segala sesuatunya tetap mengikuti prosedur yang telah ditetapkan yakni membayar denda. Satuan lingaual pada data (5) ini menunjukkan identitas pemroduksi teks yang memiliki sifat kemanusiaan yang tiggi tetapi tetap tegas dengan aturan, karena orang yang ditolong tidak serta merta lepas dari tanggung jawabnya setelah ditolong dari masa sulit. Dia juga harus memberikan kontribusi terhadap pelayaran yang sedang berjalan.

Persoalan selanjutnya yang menjadi salah satu bagian penting dalam UUL adalah perkara membuang barang bawaan.

Data (6)

Tatkala ribut dan hendak membuang ke laut, nakhoda hendaklah musyawarat dengan segala nakhoda di dalam jung, karena membuang itu harus atas jumlah barang yang dibawa. (UUL: Butir 10.1)

Dalam keadaan darurat akibat badai, gelombang besar atau hal hal 
Jurnal Ilmu Budaya, Vol. 17, No. 2 Februari Tahun 2021

lain yang mengharuskan membuang barang, maka prinsip musyawarat sangat diutamakan. Satuan lingual pada data (6) ini merepresentasikan pola prioritas yang yang harus diambil jika kondisi darurat dan harus membuang barang untuk kepentingan keselamatan bersama. Dari segi relasinya, wacana pada data (5) ini mengungkap tindakan yang harus diambil pada saat darurat di laut, sedangkan dari segi identitas teks dapat diketahui bahwa pemroduksi teks lebih mengutamakan keselamatan jiwa dan raga para pelayar, dan tindakan membuang ini dianggap sangat penting.

Perkara penting lainnya yang diatur dalam UUL adalah tentang ruangan-ruangan khusus di dalam kapal yang tidak semua orang bisa memasukinya.

Data (7)

Awak perahu tidak dibenarkan duduk di tempat tertentu di dalam jung, yaitu balai lintang, balai bujur dan alang Muka (UUL: Butir 11.1.)

1. Balai Lintang, adalah salah satu kawasan khusus di dalam kapal, yakni sebagai tempat untuk berkumpul, berdiskusi, dan konsultasi. Namun, tempat ini tidak boleh digunakan sembarangan, tidak seorangpun diperbolehkan masuk ke Balai Lintang, kecuali ada kebutuhan yang sangat penting atau menyangkut kepentingan bersama (Swantoro: 2015).

2. Balai Bujur, adalah kawasan khusus di dalam kapal yakni ruang yang ditempati untuk mengendalikan arah kapal.Orang yang pergi dan tinggal di tempat ini, akan dihukum 3 kali cambuk (Swantoro, 2015).

3. Alang Muka, adalah kawasan khusus di dalam kapal, yakni yang berada di depan kabin. Orang yang boleh masuk ke wilayah ini adalah nakhoda, tukang tengah, tukang kanan, dan tukang kiri. Apabila ada awak kapal atau orang lain yang pergi ke Alang Muka, maka akan dikenakan hukuman 3 kali cambuk (Swantoro, 2015). 
Jurnal Ilmu Budaya, Vol. 17, No. 2 Februari Tahun 2021

Data (7) merepresentasikan betapa detilnya aturan-aturan dalam UUL ini, yang juga mengatur zona yang boleh dan tidak boleh dilewati kecuali orang tertentu saja. Area yang dikhususkan untuk orang-orang tertentu ini dimaksudkan untuk membuat teraturnya urusan-urusan pelayaran. Zona yang terbatas tersebut bersifat khusus karena terkait keputusan-keputusan penting yang mesti dibuat oleh orang-orang yang memiliki posisi penting dalam pelayaran.

Pemroduksi teks UUL ini adalah para Sultan dan para pemuka Melayu yang visioner yang memahami persoalan job description dalam pelayaran. Pada sisi identitas, pemroduksi teks menggambarkan situasi, kondisi, latar dan peristiwa di dalam sebuah perahu dan cenderung memihak kepada semua pihak yang terlibat. Pembatasan area-area tertentu menunjukkan manajeman yang baik. Jika sewaktu-waktu keadaan darurat dan mengharuskan musyawarat maka sudah ada tempat khusus dan pada saat mengambil keputusan, orang-orang yang tidak berkepentingan tidak boleh masuk atau mengganggu.

\section{Simpulan}

Secara umum UUL merepresentasikan peristiwa-peristiwa dan aktivitas-aktivitas dalam pelayaran. Mulai dari tugas nakhoda dan awak perahu, antara lain tukang agung, tukang tengah, kanan, tukang kiri, juru mudi, juru batu, gantung, Mualim dan senawi sampai hak dan kewajiban seluruh pelayar. Istilahistilah lainnya seperti kiwi, mulkiwi, ruangan khusus: Balai Lintang, Balai Bujur, Alang Muka. Aspek bahasa lingkungan kelautan lainnya seperti laut, pulau, dermaga dan sebagainya. Satuan lingual yang digunakan dalam UUL untuk merepresentasikan para pelayar adalah penggunaan diksi, kalimat pernyataan, kalimat sebab akibat berupa denda ataupun hukuman bagi pelanggar. Pada tataran relasi, UUL dibuat berkenaan dengan tugas dan kewajiban para pelaut yang melakukan pelayaran, dan pada tataran 
Jurnal Ilmu Budaya, Vol. 17, No. 2 Februari Tahun 2021

identitas teks UUL ini para sultan dan pemimpin Melayu sebagai pemroduksi teks menggambarkan situasi dan aktivitas yang cenderung memihak kepada orang-orang yang memiliki jabatan.

Penelitian ini hanya membahas tentang representasi, relasi dan identitas teks dalam UUL dengan pendekatan ekolinguistik kritis. Data yang dibahas juga hanya sebagian sebagai representasi data yang ada. Masih banyak persoalan yang bisa dibahas dalam penelitian selanjutnya.

\section{Daftar Pustaka}

Alwi, Hasan, dkk. 2005. Kamus Besar Bahasa Indonesia, edisi ketiga. Jakarta Balai Pustaka

Djajasudarma. 2006. Metode Linguistik Ancangan Metode Penelitian dan Kajian. Bandung: PT. Eresco.

Edorita, Widia. 2018. "Implementasi Nilai-nilai Adat dan Kearifan Lokal dalam Melestarikan Hutan, Sungai dan Danau Desa Buluh Cina Kecamatan Siak Hulu, Kabupaten Kampar" Riau Law Journal Vol. 2 No.2, November 2018. https://ejournal.unri.ac.id/index.php /RLJ/article/download/6201/5860
Eriyanto. 2009. Analisis Wacana Pengantar Teks Media. Yogyakarta: PT. LKiS Printing Cemerlang.

Fairclough, Norman. 1995. Critical Discourse Analysis: The Critical Study of Language. Harlow-Essex: Longman Group Limited.

Fang, Yock Liaw. 2016. Sejarah Kesusasteraan Melayu Klasik. Jakarta: Yayasan Pustaka Obor Indonesia

Fill, A. \& Mühlhäusler, P. 2001. The Ecolinguistics Reader. Language, Ecology, and Environment. London \& New York: Continuum

Hijiriyah, Siti. 2017. "Kajian Struktur, Fungsi, Dan Nilai Moral Cerita Rakyat Sebagai Bahan Pembelajaran Apresiasi Sastra". Riksa Bahasa. Vol. 3. No.1

Jismulatif and Dahnilsyah. 2019. "Language and Ecolgy in Ecolinguistics perspective: A case Study on Tunjuk Ajar Language in Riau, Indonesia". Journal of Physics Conference Series. Vol. 1351

Junaidi. 2019. "Spirit of Maritime in Rida K.Liamsi's poems". International Journal of Innovation, Creativity and Change. www.ijicc.net . Volume 5 (2): 1240-1254 
Jurnal Ilmu Budaya, Vol. 17, No. 2 Februari Tahun 2021

Mbete, Aron Meko dan Abdurrahman Adisaputera. 2009. "Penyusutan Fungsi Sosioekologis Bahasa Melayu Langkat Pada Komunitas Remaja Di Stabat, Langkat."

Mahardhika, Kholifatu Nurlaili \& Kramadibrata, Dewaki. 2020. "Sanksi Pidana dalam Teks Naskah Undang-Undang Hukum Laut" Jurnal Manassa. Vo. 10. No. 2

Mahsun. 2005. Metode Penelitian Bahasa: Tahapan Strategi, Metode, dan Tekniknya. Jakarta: Raja Grafindo Persada.

Samin, Rumzi. 2018. "Perahu Lancang Kuning Kearifan Lokal Masyarakat Melayu Bintan Kepulauan Riau". Jurrnal Ilmu Administrasi Negara(JUAN). 2(6): 9-13

Sinar, T. S. 2010. "Ungkapan Verbal Etnis Melayu dalam Pemeliharaan Lingkungan." Disampaikan dalam Seminar Internasional Seminar Language, Literature, And Culture in Southheast Asia. Diselenggarakan oleh Prodi Linguistik USU dan Phuket Rajabhat University Thailand, Thailand 3-5 Juni 2010.

Stibbe, Arran. 2015. Ecolnguistics: language, ecology, and the stories we live by. London and New York: Routledge.

Sudaryanto. 2016. Metode dan Aneka Teknik Analisis Bahasa.
Yogyakarta: Duta Wacana University Press.

Suwardi. 2016. Undang-Undang Laut Dalam Sejarah Kesusastraan Melayu Klasik. Prosiding Konferensi Nasional Sejarah X. Budaya Bahari dan Dinamika Kehidupan Bangsa dalam Persepektif Sejarah. -10 November 2016. Direktorat Sejarah.

Swantoro, Aris. 2015. Tim Pengkajian Hukum Tentang Kontribusi Hukum Adat Dalam Pengembangan Hukum Laut di Indonesia. https://www.bphn.go.id/data/docum ents/kontribusi_hukum_adat_dlm_p engembangan_hkm_laut_di_indone sia.pdf) 